\title{
Avaliação de um sistema de ovinocultura intensificada baseado em campo nativo no Rio Grande do Sul
}

\section{Evaluation of an intensified sheep farming system based on nature pasture in Rio Grande do Sul}

Itubiara Maciel da Silva ${ }^{1}$, Marcus Vinícius Bentancur Fernandes ${ }^{2}$, Leonardo de Melo Menezes*3

\section{RESUMO}

O presente trabalho teve o objetivo de realizar uma análise acerca da produção ovina em um sistema de cria intensivo, através da técnica do creep feeding; ainda, realizar um estudo comparativo entre este sistema e outras atividades agrícolas tradicionais realizadas no Rio Grande do Sul. O experimento foi conduzido no município de Santana do Livramento e compreendeu o período de julho a dezembro de 2020. Realizou-se o cálculo da receita bruta por hectare desta produção ovina intensificada, servindo este critério como base de comparação para as atividades arroz irrigado, soja e bovinocultura de corte. A ovinocultura intensificada por uso de creep feeding apresenta receita bruta intermediária quando comparada a atividades agrícolas tradicionais no Rio Grande do Sul. Entretanto, apresenta elementos importantes que podem representar estímulos ao produtor, como menor risco, baixa necessidade de insumos externos e mercado em expansão.

Palavras-chave: Bioma pampa; carne ovina; creep feeding; pastagens naturais

\begin{abstract}
The present work had the objective to carry out an analysis about the sheep production in an intensive rearing system, through the creep feeding technique; also, carry out a comparative study between this system and other traditional agricultural activities carried out in Rio Grande do Sul. The experiment was conducted in the municipality of Santana do Livramento and covered the period from July to December 2020. Gross revenue was calculated per hectare of this intensified sheep production, this criterion serving as a basis for comparison for irrigated rice, soy and beef cattle activities. Sheep farming intensified by the use of creep feeding has an intermediate gross income when compared to traditional agricultural activities in Rio Grande do Sul. However, it presents important elements that can represent incentives to the producer, such as lower risk, low need for external inputs and an expanding market.
\end{abstract}

Keywords: creep feeding; natural pastures; Pampa Biome; sheep meat

\footnotetext{
${ }^{1}$ Mestrando em Zootecnia, Universidade Federal do Rio Grande do Sul - UFRGS

${ }^{2}$ Graduando em Agronomia, Universidade Estadual do Rio Grande do Sul - UERGS

${ }^{3}$ Professor Adjunto, Universidade Estadual do Rio Grande do Sul - UERGS
} 


\section{INTRODUÇÃO}

O agronegócio brasileiro contemporâneo é reconhecido pela grande participação na balança comercial, uma vez que a exportação de diversos produtos contribui para o superávit do país. Na safra 2016/2017 o agronegócio somou 96 milhões de dólares, correspondendo a 44,8\% das exportações totais (IBGE, 2017). Atualmente o Brasil exporta diversos produtos para 189 países e a União Europeia, dentre eles carne suína, de frango, produtos lácteos, material genético, peixe, carne bovina e grãos (SILVA, 2018). O PIB agrícola representa cerca de $25 \%$ da riqueza nacional, gera $1 / 3$ dos empregos e é responsável por 50\% das exportações (BRASIl, 2020).

O Rio Grande do Sul (RS) é considerado um dos principais colaboradores nacionais com 11,6\% no Valor Adicionado Bruto (VAB) que compõe o Produto Interno Bruto (PIB) do país no setor agropecuário, seguido por Paraná com 11,4\% e São Paulo com 10,9\% (FEIX et al., 2017). De acordo com Atlas Socioeconômico do RS (2019), na pecuária, a bovinocultura de corte é a principal atividade realizada com importância social e econômica. A carne in natura bovina corresponde a 6,29\% das exportações sendo o segundo colocado do setor agropecuário (EMBRAPA, 2017). O rebanho bovino é composto por mais de 13 milhões de cabeças, sendo o sétimo colocado, dentre os estados da federação (IBGE, 2017). O rebanho ovino no RS destaca-se como o segundo maior rebanho brasileiro (3,4 milhões de cabeças), estando atrás apenas do estado da Bahia, com 3,7 milhões de cabeças (IBGE, 2017).

A ovinocultura é uma atividade realizada principalmente em conjunto com a espécie bovina, porém não se apresenta de forma tão expressiva quanto a bovinocultura. O sistema geralmente é extensivo e ainda limitado pela necessidade de técnicas reprodutivas e manejos sanitários mais eficientes que agregariam um aumento na produção (SILVA et al., 2013). O manejo nutricional dos rebanhos frequentemente é negligenciado, ficando aquém do potencial produtivo (MENEZES et al, 2017; MUNHOZ et al, 2020). Em relação ao consumo de carne ovina, nota-se um expressivo aumento nos últimos anos. É fato que o atual cenário da ovinocultura nacional, aliado às exigências do mercado consumidor, está direcionado para a intensificação da produção e aumento em termos quantitativos e qualitativos de carcaças ovinas. Neste sentido, a produção em maior volume de animais jovens é uma demanda crescente. Uma técnica que pode ser utilizada para produção de animais pesados a idades jovens é o creep feeding (MENEZES 
et al, 2021). Consiste na suplementação alimentar, durante a fase de cria, utilizando alimentos volumosos de alta qualidade, concentrados, suplementos minerais e vitamínicos, efetuada em um cocho cercado de forma a permitir somente a entrada das crias; desta forma, permanecem as matrizes (ovelhas lactantes) excluídas do sistema. Além de aumentar o ganho de peso das crias no desmame, o creep feeding contribui ainda para a redução do desgaste das matrizes, em função do menor consumo de leite por parte dos cordeiros. Este efeito benéfico é percebido principalmente em primíparas que pariram em reduzido estado de condição corporal (NEIVA et al, 2004).

Como principal limitante destaca-se o incremento nos custos com a alimentação dos cordeiros. Por todo o exposto, este estudo buscou avaliar um sistema de ovinocultura intensificada, ainda que alicerçada em campo nativo, base da criação de ovinos do sul do Brasil; ainda, em um segundo momento, buscou-se traçar um comparativo desta com outras atividades tradicionais realizadas no Rio Grande do Sul como soja, arroz e bovinocultura de corte.

\section{MATERIAL E MÉTODOS}

O experimento foi conduzido no município de Santana do Livramento (RS), em uma propriedade situada no $5^{\circ}$ distrito denominado São Diogo, há $87 \mathrm{~km}$ do centro do município, coordenadas geográficas $-30^{\circ} 19^{\prime}$ 41.77718’ S -55³9’51',69262’ W. Foram utilizadas ovelhas multíparas da raça Ideal, previamente acasaladas com carneiro da raça Merino Australiano. O período experimental compreendeu os meses de julho a dezembro de 2020. O período de parição dos animais experimentais estendeu-se entre os dias 25 de julho e 10 de agosto de 2020. Neste período, foram selecionados 30 cordeiros (as), sendo 15 fêmeas e 15 machos, oriundos exclusivamente de partos simples. O curto período de diferença (em dias) entre o primeiro e último cordeiro nascido foi previamente planejado, a fim de permitir maior homogeneidade do lote estudado. Os animais foram identificados ao nascimento, registrando-se o peso ao parto. A partir de então, foram manejados em conjunto com as mães, em uma área de cinco hectares.

No dia 14 de agosto os animais foram novamente pesados e iniciou-se a suplementação com ração comercial contendo $18 \%$ de proteína bruta, em cochos adaptados ao sistema creep feeding. A oferta diária foi de $1 \%$ do peso vivo dos cordeiros, sendo ajustada a cada 21 dias. Para mensuração do peso dos animais utilizou-se balança eletrônica com precisão de 100 gramas. Foram realizadas um total de seis pesagens 
durante o período, registrando-se os dados em planilhas eletrônicas. O período de suplementação foi de 90 dias, sendo finalizado ao dia 03 de dezembro, data de desmame dos cordeiros.

Ao término do período experimental, todos os cordeiros foram novamente pesados, calculando-se o número total de $\mathrm{kg}$ de cordeiros machos (destinados à venda $\mathrm{e}$ abate) produzidos pela soma aritmética dos dados. Em relação às cordeiras nascidas, considerou-se a venda de animais excedentes a necessidade de reposição. Neste caso, das 15 cordeiras nascidas considerou-se que sete seriam destinadas a comercialização. Os dados referentes a produção de lã de ovelhas e cordeiros também foram registrados. Considerou-se ainda uma taxa de descarte de matrizes de $20 \%$, ou seja, 6 ovelhas.

A partir destes dados possibilitou-se calcular a receita bruta obtida por hectare (RBha) deste sistema através da seguinte fórmula:

$\mathrm{RBha}=$ quilos de cordeiro produzidos $*$ preço $(\mathrm{R} \$) / \mathrm{kg}+$ quilos de lã de cordeiro produzido* preço $(\mathrm{R} \$) / \mathrm{kg}+$ quilos de lã das ovelhas e carneiro* preço $(\mathrm{R} \$) / \mathrm{kg}+$ quilos de ovelhas de descarte* preço $(\mathrm{R} \$) / \mathrm{kg}$

Área (hectares)

Considerou-se que as ovelhas de descarte pesaram em média $60 \mathrm{~kg}$ de peso vivo.

Os preços considerados neste estudo foram valores obtidos através da média de uma pesquisa no mercado informal e de preços divulgados pela EMATER, no mês de dezembro de 2020. De posse de todos estes dados a receita bruta de todo o sistema pode ser calculada. Para as atividades soja, arroz e bovinocultura de corte, utilizou-se dados estatísticos do IBGE, divulgados no Agrolink (2021). A partir do cruzamento entre os dados de produção média por hectare divulgada e os preços de mercado estimou-se a receita bruta de cada atividade por hectare.

\section{RESULTADOS E DISCUSSÃO}

A receita bruta por hectare obtida com a produção deste sistema intensificado está devidamente discriminada e pode ser visualizada na tabela 1.

Tabela 1 - Receita bruta por hectare (RBha) de um sistema intensificado de produção ovina através da técnica de creep feeding baseado em campo nativo. 


\begin{tabular}{|c|c|c|c|c|c|c|}
\hline \multicolumn{7}{|c|}{ Receita Bruta por hectare (Rbha) } \\
\hline Item & Unidades & $\begin{array}{l}\text { Total de kg } \\
\text { produzidos }\end{array}$ & $\begin{array}{r}\text { Valor } \\
(\mathrm{R}\end{array}$ & $\begin{array}{l}\text { unitário } \\
/ \mathrm{kg} \text { ) }\end{array}$ & & total $(\mathrm{R} \$)$ \\
\hline Cordeiros & 15 & 492,15 & $\mathrm{R} \$$ & 8,50 & $\mathrm{R} \$$ & $4.183,28$ \\
\hline Cordeiras & 7 & 227,5 & $\mathrm{R} \$$ & 8,50 & $\mathrm{R} \$$ & $1.933,75$ \\
\hline Lã de cordeiros & 30 & 17,19 & $\mathrm{R} \$$ & 8,00 & $\mathrm{R} \$$ & 137,52 \\
\hline Lã de ovelhas/carneiro & 31 & 121,706 & $\mathrm{R} \$$ & 19,50 & $\mathrm{R} \$$ & $2.373,27$ \\
\hline Ovelhas descarte & 6 & 360 & $\mathrm{R} \$$ & 6,60 & $\mathrm{R} \$$ & $2.376,00$ \\
\hline Receita bruta total & & & & & $\mathrm{R} \$$ & $11.003,81$ \\
\hline Receita bruta por hectar & & & & & $\mathrm{R} \$$ & $2.200,76$ \\
\hline
\end{tabular}

A principal receita deste sistema foi obtida pela produção de cordeiros (machos), na qual gerou-se a produção de 492,1 kg (peso médio de $32,8 \mathrm{~kg}$ ), comercializados a valor unitário de $\mathrm{R} \$ 8,50 / \mathrm{kg}$ ( $\mathrm{R} \$ 278,88$ por animal), totalizando $\mathrm{R} \$ 4.183,28$. Os dados são semelhantes aos de Tonetto et al. (2004) que encontraram cordeiros aptos ao abate pesando em torno dos $31 \mathrm{~kg}$, quando mantidos com suas mães; os dados também vão de encontro com o s dados obtidos por Figueiró (1989), que descreve que a idade de abate dos cordeiros deve ser entre 90 e 100 dias, com peso vivo de 25 a $30 \mathrm{~kg}$ ao abate. Neste sentido, verifica-se que a implementação da técnica apresenta potencial para gerar carnes e carcaças com padrão de qualidade exigido pelo mercado.

Em relação ao descarte das ovelhas (mães), considerou-se a comercialização de seis ovelhas, correspondente a $20 \%$ das fêmeas utilizadas no experimento. Estas deixam o sistema anualmente devido a falha reprodutiva, idade avançada ou baixo nível de produtividade. Estes critérios de seleção são confirmados por Azambuja et al (2012), que explicam que a prática de descarte parte de uma necessidade de identificação e na remoção dos animais improdutivos ou menos produtivos do rebanho. Pode-se perceber que embora sejam poucos animais (6), estes contribuem significativamente para o sistema, a ponto de sua receita equiparar-se a receita obtida com a venda de lã dos animais adultos.

Segundo o estudo realizado por Viana e Silveira (2009) a comercialização de lã apresenta parcela significativa da receita total em uma propriedade rural. Em um rebanho como o estudado, representado por raças com aptidão laneira, a importância do produto lã no sistema produtivo de ovinos agrega receita na propriedade. Ainda assim, a variação 
no preço da lã observadas nos últimos anos pode alterar significativamente a contribuição deste produto para o sistema.

A receita bruta total do sistema avaliado foi de $\mathrm{R} \$ 11.003,81$. Considerando-se a área utilizada (cinco hectares), a receita bruta por hectare foi de R2 2.200,76.

A seguir serão apresentadas as receitas brutas obtidas com outras atividades agrícolas e pecuárias, a fim de traçar uma análise comparativa.

Tabela 2. Receita Bruta por hectare de atividades agropecuárias, desenvolvidas no estado do RS.

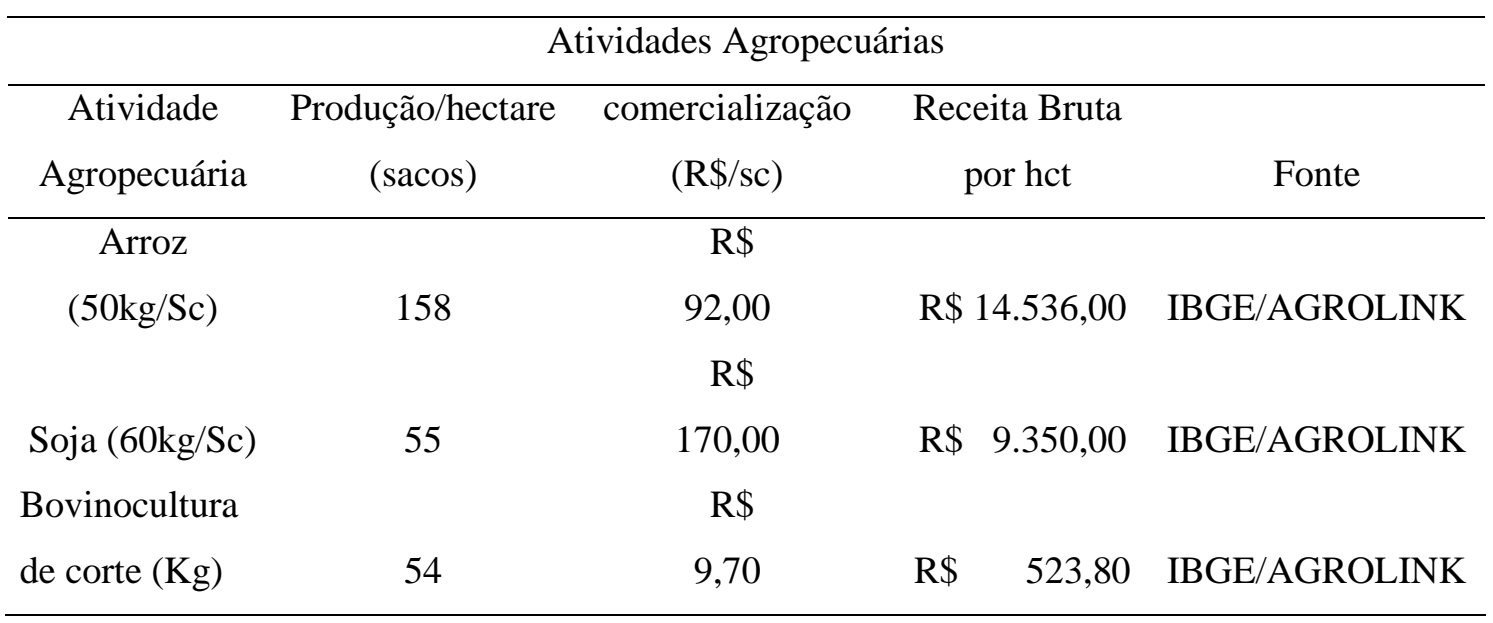

De acordo com a tabela 2, podemos identificar a produtividade de outras atividades praticadas no estado do Rio Grande do Sul, no qual destacamos o arroz com alta produtividade e receita bruta por hectare, somando $\mathrm{R} \$ 14.536,00$. Na sequência, a atividade soja, com produtividade média de 55 sacas por hectare totalizando uma receita bruta por hectare de 9.350,00, considerando os preços médios praticados na última safra. A bovinocultura de corte tradicional (baseada em campo nativo com baixa utilização de tecnologia) apresenta uma produtividade média de $54 \mathrm{~kg}$ de carne produzida por hectare/ano gerando uma receita bruta por hectare (atualizada para valores atuais) de R\$ 523,80 (Dias, 2011).

A cultura do arroz, de acordo com (IRGA, 2020), apresentou custo médio de $\mathrm{R} \$$ 64,70 por saco de $50 \mathrm{~kg}$ produzido no Rio Grande do Sul. Com base neste cálculo, o custo por hectare é de $\mathrm{R} \$ 10.078,00$, considerando uma média de produtividade de 7.788,26 $\mathrm{kg} / \mathrm{ha}$, ou seja, 155,77 sacos/ha. Nota-se um custo superior a $70 \%$ do valor comercializado ( $\mathrm{R} \$ 92,00)$ na safra 2021. Ao considerarmos os preços praticados na safra passada 
( $\mathrm{R} \$ 49,40 /$ saco, de acordo com o CEPEA), verificamos que a atividade estaria operando em prejuízo, considerando a produtividade média do estado. Além disso, as barreiras de entrada para a atividade arrozeira são muito maiores em comparação com a ovinocultura, especialmente no que diz respeito a aquisição de maquinário, aptidão de solo e relevo e dependência de insumos externos como diesel, fertilizantes e defensivos, muitas vezes cotados à dólar.

Segundo Nascimento (2020), o custo de produção da safra 2020/21 de soja no Rio Grande do Sul foi estimado em $\mathrm{R} \$ 4.800,76$ por hectare. O valor é 31,78\% superior aos $\mathrm{R} \$ 3,643$ mil por hectare na safra passada. Se considerado apenas o desembolso, o valor fica em $\mathrm{R} \$ 3.098,25$ por hectare, uma alta de $29,98 \%$ ante $20 / 21$.

Analisando o custo de produção do arroz e da soja, fica evidente o alto custo de produção, onde podemos citar, os insumos como mão-de-obra especializada, sementes, adubos, fertilizantes, defensivos agrícolas, preparo do solo, aviação, irrigação, colheita, pós-colheita, ou seja, todo o processo que envolve a produção destes grãos, assim onerando a produção agrícola (Santana et al. 2006). Por todo o exposto, fica explicitado o alto risco envolvido na produção agrícola, somado às incertezas relacionadas aos crescentes custos de produção, que não são acompanhados pelo aumento proporcional do valor das commodities, na maioria das safras subsequentes. Como vantagem, tanto a cultura de arroz quanto a da soja são realizadas em apenas uma época do ano, permitindo a utilização da área (ou de parte dela) para outras atividades no período de entressafra.

De acordo com Dias (2011), no Rio Grande do Sul a produção anual média de carne por hectare gira em torno de 54 quilos $(\mathrm{kg}) / \mathrm{ha}$. Esta pecuária considera baixa utilização de tecnologia, pastejo extensivo e contínuo, e, reduzida ou nenhuma suplementação, salvo a utilização de sal mineral aos animais. Este modelo de produção é dependente de uma grande escala produtiva, visto que a receita bruta/ha é a mais baixa no comparativo realizado neste trabalho, calculado em $\mathrm{R} \$ 523,80$. O aumento da escala produtiva por aumento de área, entretanto, tem sido dificultado no Brasil nos últimos anos. Entre os fatores que explicam esta situação estão os dados explicitados neste trabalho, demonstrado que outras atividades, mais intensivas e que utilizam tecnologia em seus processos, aumentam a competição pelo uso da terra.

Desta forma, a ovinocultura vem surgindo como alternativa, podendo ser executada em áreas pequenas ou maiores, por produtores familiares até os mais 
tecnificados. Neste sentido, é importante para gerar produtos destinados tanto para a subsistência quanto para comercialização. De forma geral, a dependência de insumos externos é menor quando comparada com as outras culturas; a utilização de técnicas que intensifiquem a produção devem ser priorizadas, especialmente aquelas voltadas à nutrição dos cordeiros, já que apresentam rápido ciclo produtivo (cerca de 120-150 dias).

\section{CONCLUSÃO}

A ovinocultura intensificada por uso de creep feeding apresenta receita bruta intermediária quando comparada a atividades agrícolas tradicionais no Rio Grande do Sul. Entretanto, apresenta elementos importantes que podem representar estímulos ao produtor como o menor risco, a baixa necessidade de insumos externos e mercado em expansão. Mais estudos devem ser realizados, considerando mais variáveis e inclusão de custos em distintos cenários produtivos.

\section{REFERÊNCIAS}

AGROLINK .Cotações agropecuárias. Site:Agrolink o portal do conteúdo agropecuário. Disponivel em:< https://www.agrolink.com.br/cotacoes $>$. Acesso em 27 de Dez 2020.

AZAMBUJA, R. C. C.; CARDOSO, F. F.; YOKOO, M. J.; DIONELLO, N. J. L.; ALVES, R. M.; LÔBO, R. N. B. Valores econômicos para características produtivas emo vinos: desenvolvimento de objetivos e critérios de seleção e sistemas de produção baseados em pastagem native no bioma Pampa do Brasil. In: IX Simpósio Brasileiro de Melhoramento Animal. 2012. João Pessoa-PB. Anais[...] João Pessoa-PB, 2012.

ATLAS SOCIOECONÔMICO RIO GRANDE DO SUL. Bovinos: O RS possui 6,5\% do rebanho bovino do Brasil. 4. ed. Porto Alegre: Secretaria de Planejamento,Orçamento e Gestão, 2019. Disponível em https://atlassocioeconomico.rs.gov.br/participacao-do-pib-estadual. Acesso em: 12 abr. 2021.

BRASIL. Estatísticas de Comércio Exterior do Agronegócio Brasileiro. Brasília-DF, 2020. Disponível em:http://indicadores.agricultura.gov.br/agrostat/index.htm. Acesso em 05 nov. 2021.

DIAS, V. FMVZ eleva produção de carne para 600 quilos por hectare. Site: Agencia USP de notícias. Disponivel em http://www.usp.br/agen/?p=73472 Acesso em: 11 jun 2021. 
EMBRAPA - Empresa Brasileira de pesquisa Agropecuária. Carne em números: principais produtos exportados em 2016. Disponível em

https://www.embrapa.br/qualidade-da-carne/carne-bovina. Acesso em: 12 abr. 2020.

FEIX, R. D.; LEUSIN JÚNIOR, S; BORGES, B. K. Painel do Agronegócio no Rio Grande do Sul - 2017. Porto Alegre, RS: FEE, 2017. p.8.

FIGUEIRÓ, P.R.P. Manejo alimentar do rebanho ovino. In: SIMPÓSIO PAULISTA DE OVINOCULTURA, 1., 1989, Campinas. Anais... Campinas: Fundação Cargil, 1989. p.22-33.

GUIMARÃES F, C. Manejo básico de ovinos e caprinos: guia do educador. Serviço Brasileiro de Apoio às Micro e Pequenas Empresas - SEBRAE 2009.

INSTITUTO BRASILEIRO DE GEOGRAFIA E ESTATÍSTICA - IBGE. Dados Estatísticos e Censo Agropecuário. 2017. Disponível em:

https://censos.ibge.gov.br/agro/2017/ . Acesso em: 13 dez. 2020.

IRGA. Irga divulga custo de produção da safra 2020/2021. Site: IRGA - Instituto Rio Grandense de arroz. Disponivel em: < https://irga.rs.gov.br/irga-projeta-semeaduraem-969- 192-ha-na-safra-2020-2021 > Acesso em: 12 jun 2021

MENEZES, L. M.; FONTOURA, E. A. B.; TÂMARA, J. Q.; MUNHOZ, M. L.; RODRIGUES, D. P.; GOMES, A. F. F. Produção leiteira de ovelhas Texel submetidas a suplementação. Research, Society and Development, [S. 1.], v. 10, n. 2, pe 30010212500, 2021.

MENEZES, L. M., FONTOURA, E. A. B., DAMILANO, A. S., ROSA, R. S., PEREZ, H. A., GOMES, A. F. F., CUNHA, P. T., CHAGAS, R. A., CORREAA, G. F. Desempenho de cordeiros Texel e Corriedale mantidos em azevém em fim de ciclo. Revista electrónica de Veterinaria. 18(12):1-9. 2017.

MUNHOZ, M. L., FONTOURA, E. A. B., RODRIGUES, D. P., MOREIRA, C. H., RODRIGUES, P. E. B., CORDEIRO, D. O., SANTANA, G. A. O. \& MENEZES, L. M. (2020). Desempenho de ovelhas e cordeiros Texel em distintas fases do manejo nutricional. Brazilian Journal of Development, 6, 4909-4919.

NASCIMENTO, G. Custos de produção da safra 2021/22 de soja sobem 31,78\% no RS, FECOAGRO. Site: Safras\&Mercados. Disponível em https://news.safras.com.br/custos-de-producao-da-safra-2021-22-de-soja-sobem-3178no-rs-diz-fecoagro/ Acesso em: 12 jun 2021.

NEIVA, J. N. M.; CAVALCANTE, M. A. B.; ROGÉRIO, M. C. P.; Uso do creep feeding na criação de ovinos e caprinos. In: $8^{\circ}$ Seminário Nordestino de Pecuária. Anais... 2004.

NERES, M. A, et al. Níveis de feno de alfafa e forma física da ração no desempenho de cordeiros em creep feeding. Revista Brasileira de Zootecnia, v. 30, n. 3, p. 941 - 947, 2001 (supl. 1).

SANTANA, A. C.; FILGUEIRAS, G. C.; ROCHA, C. F. G. Arranjos produtivos locais da BR263: contribuições ao planejamento estratégico territorial. Belém: ADA, 2006. 
SILVA, A.P.S.P.; SANTOS, D.V.; KOHEK JR, I.; MACHADO, G.; HEIN, H.E.; VIDOR, A.C.M.; CORBELLINI, L.G. Ovinocultura do Rio Grande do Sul: descrição do sistema produtivo e dos principais aspectos sanitários e reprodutivos. Pesquisa Veterinária Brasileira 33(12):1453-1458, dez. 2013

TONETTO, C. J. et al. Ganho de Peso e Características da Carcaça de Cordeiros Terminados em Pastagem Natural Suplementada, Pastagem Cultivada de Azevém(Lolium um tiflorum Lam.) e Confinamento. Revista Brasileira de Zootecnia, vol. $33 \mathrm{n}^{\circ} .1$.

VIANA J. G. A.; SILVEIRA V. C. P. Análise econômica da ovinocultura: estudo de caso na Metade Sul do Rio Grande do Sul, Brasil. Ciência Rural. v. 39, n. 4, p.11761181.2009.

Recebido em: 20/10/2021

Aprovado em: 10/11/2021

Publicado em: 18/11/2021 